\title{
GEOGRAFIA HUMANA E DETERMINAÇÃO
}

\section{HUMAN GEOGRAPHY AND DETERMINATION}

\author{
Kevin R. Cox \\ cox.13@osu.edu \\ Professor do Departamento de Geografia da Ohio State University \\ (Tradução do Inglês por Pedro Geiger)
}

\section{RESUMO}

A noção de indeterminação e de geografias possíveis possui uma longa história na Geografia Humana. Ela tem sido pensada em termos de um número de diferentes contrastes típicos, como os de indeterminação/determinação; contingência/necessidade; agenciamento/estrutura; composição/contexto. Este artigo provê, primeiro, uma revisão sobre como a questão foi enquadrado desde a revolução quantitativa espacial. Ela procede com os trabalhos iniciais de autores como Hagerstrand e Curry até chegar a trabalhos mais recentes, como sobre o desenvolvimento encaminhado, ou sobre as justaposições de chance de Massey. As continuidades e complementaridades entre estas diferentes abordagens são focalizadas. $\mathrm{O}$ artigo conclui discutindo como se pode pensar a indeterminancia na geografia humana de forma mais defensiva, e como o materialismo histórico geográfico permite nos movermos para além destes binômios.

Palavras chave Indeterminancia. Justaposição por chance. Desenvolvimento dependente de encaminhamento. Geografias históricas. Materialismo histórico geográfico.

\begin{abstract}
.
The notion of indeterminacy and possible geographies has a long history in human geography. It has typically been thought of in terms of a number of different contrasts: indeterminacy/determinacy; contingent/necessary; agency/structure; composition/context. In the first place this paper provides a review of how the question has been framed since the spatial-quantitative revolution. This proceeds from the early works of people like Hagerstrand and Curry through the more recent work on path dependent development and Massey's chance juxtapositions. The continuities and complementarities between these different approaches are highlighted. The paper concludes with a discussion of how we might more defensible think about indeterminacy in human geography and how historical geographical materialism allows us to move beyond these binaries
\end{abstract}

Key Words: indeterminacy; chance juxtaposition; path dependent development; geographical histories; historical geographical materialism. 


\section{Introdução.}

A idéia de indeterminência se encontra profundamente semeada, tanto na vida diária, como na teoria social. É nos dito que o futuro não pode ser antecipado e nossas vidas, para não dizer nossas histórias geográficas, reforçam tal visão. Por outro lado, no entanto, nós continuamos planejando para o futuro. O mesmo se aplica para a geografia. Geografias são apenas possibilidades, sejam elas concebidas para um futuro, ou, sejam elas concebidas como uma qualificação de predição espacial, segundo Bunge. Esta noção de indeterminação, de futuros abertos em vez de fechados, nas palavras de Massey, possui longa história na Geografia Humana. No entanto, foi apenas a partir da revolução quantitativa-espacial que este assunto passou a ser cuidadosamente escrutinado teoricamente. As pessoas passaram a pensar em formas de incorporar a noção de indeterminação em seus textos explicativos; não mais, como uma simples referência ao fato de que as pessoas fazem escolhas.

Desde então, a questão tem sido concebida de diversas maneiras, porém, sempre, como sendo alguma noção contrastante à de determinação. Chance versus determinação foi uma das formas iniciais. E então, fomos introduzidos mais tarde, na linguagem de contingência e de necessidade. Ao que se seguiu a proposição de Massey da instância do acontecer, que ela coloca em contraste à visão uni linear de progresso e de modernização, expressos nos que tem sido chamado de grandes narrativas. Em outras palavras, estabeleceuse um continuado debate na Geografia Humana sobre o tema, que remonta há cinquienta anos. A linguagem mudou, mas a questão permanece incomodando, mesmo que a sua longa história continue seguindo desconsiderada. .

Um objetivo deste artigo é o de prover uma revisão, embora seletiva, sobre como a questão da indeterminação foi tratada, desde a revolução quantitativa espacial até os movimentos seguintes. O que será seguido de um debate sobre as várias complementaridades existentes entre as diversas revisões e sobre o seu todo que, incorretamente, do meu ponto de vista, as mantém. Terminarei com uma discussão sobre como julgo podermos pensar, de forma mais defensiva, a indeterminação na geografia humana. Inicio, portanto, com uma breve discussão sobre os vários dualismos que têm sido expostos a respeito. 


\section{Conceitos de indeterminação e de seus "outros".}

A revolução quantitativa espacial foi inspirada por um forte sentimento de ordenamento na geografia humana: na localização das cidades, da indústria, e nas variadas geometrias que chegavam ao escrutínio analítico. Como as das redes de transporte ou as das geografias residenciais, nas cidades. Havia, também, uma visão, mais aparente nos trabalhos de alguns do que em outros, de que havia também um elemento aleatório na paisagem. Neste sentido, foram importantes Curry e Hagerstrand. Falou-se de economia espacial aleatória, de dispersões aleatórias de colonização, e de como modelagens probabilísticas, como as simulações Monte Carlo de Hagerstrand, poderiam lançar luz sobre migrações e difusões, de modo a elidir entendimentos mais determinísticos.

As mudanças na disciplina nos anos 70 deram lugar a uma linguagem diferente. Inicialmente, na forma do dualismo agenciamento/estrutura. Agentes eram socialmente estruturados no que faziam: eram limitados e habilitados, porém, um espaço era deixado para o aparecimento de novidades, já que novas práticas, não antevistas, podiam ser desenvolvidas. O interesse pelo realismo crítico, conduziu à distinção entre contingência e necessidade. As relações sociais seriam de uma, ou da outra natureza. As geografias do mundo real deveriam ser entendidas como o sendo o resultado da interseção dos dois: o exercício de propriedades causais que eram necessárias, mas cuja expressão empírica seria contingente.

Uma distinção relacionada, ainda mais radical, foi entre contexto e composição. Contingência e necessidade atuariam conjuntamente, mas, este não seria o caso de contexto e composição. As aproximações à contextualização se apóiam em noções de configuração de eventos, que, de forma muito semelhante ao da contingência do realismo crítico, não pode ser antecipada. Por outro lado, a aproximação à composição se desenha sobre o conceito geral de processo que se desenvolve, sem levar em conta os contextos. Em pensamentos mais recentes, inspirados nas fases posteriores à quantitativa, o que se vê é uma tendência a ficar com a indeterminação, como no caso da proposição da instância do acontecer de Massey. O velho dualismo foi banido, exceto como peça de museu de uma dúbia ciência social moderna. 
Porém, a questão permanece: em que extensão a particularidade é tudo isso? Não há mais lugar para o universal representado por estrutura, necessidade e composição?

Revendo o que foi dito, contaram-se acima, os seguintes dualismos: probabilidade/determinação; $\quad$ agenciamento/estrutura; $\quad$ contexto/composição; contingência/necessidade. Claramente eles não são idênticos, no sentido de que capturam diferentes aspectos da indeterminação, assim como, representam diferentes concepções de como ela atua. Nenhuma destas dualidades afirma de forma enfática que ser indeterminado significa que a coisa não é causada. Como foi expresso por Curry, usar a linguagem de chance é reconhecer a ignorância do que causou certa coisa a acontecer; no entanto, é nos possível calcular, de modo defensivo, a possibilidade de esta coisa ocorrer, com base no nosso entendimento de processo. A exemplo do uso do campo de informação de médias de Hagerstrand, como no caso da regra da redução (de uma variável) com a distância. Ao falarmos de contingência, nos aproximamos mais de uma narração geohistórica do porque algo aconteceu. Em vez de calcular as probabilidades de um encontro, podemos nomear as forças que conduziram a este encontro, que, por sua vez, levou a uma série particular de arranjos locacionais, que então puderam - mas, não obrigatoriamente - ser desenhados por forças de uma natureza mais geral: as de relações de necessidade, nos termos de Sayer. Isto pode conduzir na direção de mais reclamos específicos de contexto, em oposição aos tipos de reclamos mais universais, que não apenas Hagerstrand e Curry tinham aspirado,, como eram objetos dos geógrafos materialistas históricos. Contudo, com toda esta diversidade, eles representam, todos, as tentativas de capturar a indeterminação a ser reconhecida como algo com que temos de lidar nos estudos, não somente estudos da sociedade, como também, os de sociedade e espaço.

\section{Teorizando Possíveis Geografias: um breve levantamento.}

\section{Contribuições iniciais: de Hagerstrand a Haggett.}

Já são quase 50 anos, desde que li o estudo Migração e Área de Hagerstrand. (1957). Eu fiquei, e continuo impressionado. Neste trabalho, ele começa a tratar de geografias da migração, identificando o que ele chama de desvios da "regra declínio/distância": isto é, o caso da migração de um lugar particular para um outro ser seriamente sub-prevista, em termos da previsão segundo o modelo gravitacional. Para explicar tais desvios, ele postulou um 
processo apoiado na noção de chance e de realimentação de informação. Ele procedeu então testando os seus reclamos através das simulações Monte Carlo, para mostrar que, realmente, este processo poderia gerar padrões que eram de forma marcante semelhantes àqueles desvios observados na migração tratada.

O que me atrai, atualmente, neste trabalho, é o papel atribuído à chance: os eventos aparentemente imprevistos que resultam nas pessoas se encontrarem onde estão, às vezes, independente da atuação de amplas forças estruturadas, como as que são capturadas pelo modelo gravitacional, e minimizando o papel da distância na localização.

O interesse no processo de chance durante a revolução quantitativa espacial não pode se reduzir a Hagerstrand e às suas simulações Monte Carlo. Entre outras coisas, se relembra como eram tratados diversos modos de dispersão da ocupação pelo povoamento: da forma apinhada, numa ponta do espectro, e passando pelo aleatório, até o padrão uniforme de distribuição, na outra ponta. Distribuições aglomeradas podem ser entendidas em termos de processos fortemente aglomerativos. As uniformes podem ser compreendidas em termos de competição espacial e no desejo de criar algum monopólio espacial; já as aleatórias devem o seu caráter a diversas condições cujo papel foi difícil de ser antecipado - como, talvez, variações na fertilidade do solo, micro climas presentes, locais facilitadores de cruzamento de rios. Condições que passaram a atuar.

Portanto, uma das atrações do trabalho de Hagerstrand é a forma pela qual ele tratou de incorporar chance em hipóteses testadas de geografia humana. Também chamam à atenção suas idéias a respeito das realimentações positivas e de como poderiam ampliar diferenças iniciais. Ele verificou o reforço da cadeia da migração sendo construído de forma seqüencial. Inicialmente há um pioneiro, que migra para um dado lugar por razões inteiramente de chance. Ele, ou ela, então emite informações para trás, para parentes ou amigos, sobre as condições do lugar em que se encontra, e talvez, até providenciando ajuda para assegurar emprego, ou moradia.

No entanto, para alguns processos parece ser mais apropriado começar com os casos de apinhamentos locais que emergem numa dispersão aleatória. Peter Haggett em Locational Analysis in Human Geography toca em algo semelhante ao discutir a emergência de certas concentrações agrícolas. Condições climáticas e de solo exercem algumas limitações, porém, 
no interior das áreas limitadas, numa ampla variedade de lugares, a especialização em alguma cultura pode ocorrer. Como explicar onde isto ocorre eventualmente? O caso levantado pelo autor é o da curiosa produção de ruibarbo no West Yorkshire, entre Wakefield, Morley e Rothwell, e sua explicação se refere a "concentrações de escala em torno de um núcleo de origem aleatória”. (1965:176). Noutras palavras, uma co-presença de pelo menos alguns plantadores de ruibarbo teria sido acidental e não coordenada; no entanto, ela deu margem ao aproveitamento de algumas economias de aglomeração, como nas atividades de nivelar, de empacotar, de distribuir. O que ofereceu aos produtores de ruibarbo vantagens sobre rivais de outros lugares e estimulou a expansão da atividade. Outras singularidades, como a da produção da batata no Idaho e no Maine, podem ser explicadas de maneira semelhante. Uma vez que o núcleo é estabelecido, pode ocorrer, então, dele atiçar contínuo crescimento e levar os departamentos estaduais de agricultura a dirigirem suas capacidades de pesquisa para desenvolvimentos futuros de produção.

Tal forma de lógica me parece servir a uma aplicabilidade mais ampla. Considerem-se os exemplos a seguir.

1. Gentrificação. Em um número de cidades, a gentrificação pode se dar em áreas relativamente extensas. O estoque de domicílios é razoavelmente atrativo e se encontra próximo das áreas centrais das cidades, e das possibilidades dos empregados de colarinho branco. No entanto, isto não irá ocorrer em qualquer lugar, simplesmente porque, ou a demanda é limitada, ou porque há ansiedades a respeito dos distritos escolares do centro ${ }^{1}$. Assim como no caso das plantações de batatas, que poderiam ocorrer em diversos lugares dos Estados Unidos, não apenas em Idaho. Maine ou Michigan, mas, não ocorrem, como se explica que certas vizinhanças são selecionadas para a gentrificação e outras não? Mais uma vez, e explicação pode estar na escala da concentração num núcleo inicial aleatório. A reabilitação pode ocorrer e ocorre em qualquer lugar. Alguns moradores querem a moradia pelo menos melhorada, porém, por diversas razões, aceitam continuar residindo onde se encontram, mesmo que a vizinhança não seja a mais promissora. Um entendimento razoável é de que a distribuição da renovação é aleatória; o que significa a presença de alguns núcleos locais. Estes podem, então, prover a base para a compra e os investimentos de outras pessoas que passam a reconhecer o potencial da área. O processo é então aprofundado com a criação de uma associação da vizinhança reivindicando junto aos poderes municipais por melhorias 
do bairro, ou para persuadir donos de terrenos a tornarem os custos de amortização mais accessível.

2. A localização de migrantes nas cidades. Os migrantes de um país particular tendem a se aglomerar em certas vizinhanças, nos locais de destino. Na minha própria cidade, Columbus, se encontram diversos nódulos de mexicanos e de somalis. Isto é amplamente sabido. No século 19, o padrão se aplicava aos próprios migrantes domésticos, de cada país. Em Paris, havia distritos distintos, para bretões, para os vindos da Sabóia, do Sudoeste, e de ouras regiões. O mesmo acontecia em Londres, e não apenas com gauleses e escoceses, mas com populações vindas de diferentes países. Novamente se pode imaginar a formação de um núcleo aleatório de uma dada população migrante e o subseqüente alcance de níveis para a formação de associações culturais, ajuda mútua, empréstimos financeiros, mercearias onde a língua do migrante é falada, bancas de jornal, onde se acha impressos dos países de origem, em suma, um lar, fora dó lar, que encoraja mais concentração.

3. Um terceiro exemplo procede da literatura geográfica sobre o desenvolvimento desigual. Esta a idéia de "pulo da carniça" desenvolvida por Storper e Walker no livro deles, de 1989. O desfio é explicar como indústrias florescem e se desenvolvem em lugares inesperados. Estes são lugares que, dada a existente distribuição das indústrias, dos fornecedores, das matérias primas, dos mercados, e inclusive das vantagens de acessibilidades, não seriam esperados como capazes de atrair indústrias. Seriam lugares deficientes de infra-estrutura física e social tida normalmente como requerida. No entanto, em vista dos super lucros provenientes do desenvolvimento de um novo produto, ou de uma nova tecnologia, tais deficiências podem ser resolvidas rapidamente. Os altos salários que se estabeleceram atraem mão de obra qualificada. Linhas aéreas constroem capacidade num aeroporto adjacente ao lugar para ganhar dinheiro da expansão rápida da nova base industrial. Novas firmas fornecedoras passam a chegar, atraídos pela crescente e lucrativa demanda do que têm a oferecer. E assim por diante ${ }^{2}$. Storper e Walker tratam de uma única indústria, porém, é possível observar o potencial contido na matéria de que tratam, para a emergência de uma oportunidade de formação aleatória de um agregado de firmas de ponta em seus respectivos setores. Este, então, provê as bases para certo grau de crescimento sinergético. Um caso destacado é o do Benton County, no Noroeste de Arkansas, que em quite com o acaso, ocorre ser a sede de três entre as maiores corporações norte americanas, a Walmart, a Tysons e a J B 
Hunt Trucking. Entre 1990 e 2010, a população deste condado cresceu de 97,000 para 121.000 .

4. Estas observações sugerem uma forma de emendar os argumentos de Hagerstrand. Hagerstrand pensou em termos de uma corrente migratória gerando processos de realimentação de natureza altamente individualizada: um migrante falando para alguém, que ainda terá que realizar o movimento, das oportunidades de emprego e moradia, ou coisa parecida. Porém, o fato de Monneapolis e Calumbos serem as destinações maiores dos somalis requer uma explanação mais elaborada. Não se trata de jogar fora os entendimentos de Hagerstrand, mas para ver o problema em termos de uma justaposição de sucessivas correntes migratórias procedentes do Chifre da África. A população somali, migrante, se pos a construir no sentido de atingir limiares que facilitassem a criação do que é na essência um lar fora do lar: seus próprios shoppping centers, suas próprias igrejas, suas próprias organizações representativas, locais para encontrar parceiros matrimoniais, etc. Lembro aqui observação feita a propósito de estudo de imigrantes italianos em Montreal, no final do século 19 (BOISSEVAIN, 1970), onde eles perceberam pela primeira vez, serem todos italianos, e não, apenas, napolitanos, sicilianos, toscanos, e etc. Porém, estas seriam as origens das diferentes correntes de migrantes que acharam o seu caminho para Montreal.

Em suma, em seus estudos de migrações, Hagerstrand nos ajudou a entender a importância da chance e da subsequente realimentação; e os argumentos de Haggett a respeito das escalas de concentração em torno de um núcleo aleatório tornaram estas noções frutíferas para novos entendimentos.

Desenvolvimento dependente de um encaminhamento.

De certo modo, próximo à forma de analise observada acima, porém, tendo uma origem disciplinar diferente, é a do desenvolvimento dependente de um encaminhamento. Esta procede da economia (PAUL DAVID e BRIAN ARTHUR). O argumento deles, como o de Hagerstrand, é muito simples:

- No início pequeno, eventos de chance possuem significantes efeitos de longo prazo sobre desenvolvimentos técnicos e institucionais de uma economia. 
- Uma vez que um 'acidente`de chance é selecionado para dentro de um lugar, de forma contingente, ocorre ele ser trancado neste lugar, via externalidades em rede e crescentes retornos de escala.

- $\quad$ Esta situação persistirá e se manterá estável, até ser perturbada por um choque externo.

Casos amplamente notados deste modelo incluem a história de Betamax / VHS. Cada uma dessas firmas oferecia um vídeo tape e um sistema de impressão em fitas de vídeo incorporado numa máquina de vídeotaping. A percepção comum era de que, em termos da qualidade do registro, não haveria diferença entre as duas, embora uma percepção mais acurada mostrasse que o da Betmax era superior. Porém, esta não se tornou a tecnologia dominante e foi eventualmente retirada. Uma possível razão para tal fato foi aparentemente menor e obviamente não considerada pelos fabricantes, É que inicialmente as fitas da Betmax podiam acomodar apenas uma hora de gravação, enquanto as da VHS podiam acomodar duas horas. Em retrospectiva, um critério importante para uma família que desejasse gravar um programa de TV enquanto estivesse fora, num restaurante. Desse modo, havia uma ligeira preferência pela VHS, que passou a se alargar, quando as firmas locadoras passaram a estocar suas fitas mais do que as da Betmax. O que permitia à HVS obter crescentes retornos de escala no processo manufatureiro.

Isto naturalmente tem aplicabilidade na geografia humana, e, na verdade, geógrafos da área econômica têm mostrado muito interesse, particularmente nos debates sobre os distritos industriais e de sua supressão. Neste sentido, dependência de caminho implica também em dependência de lugar. Estar preso a um produto particular significa estar preso a uma divisão de trabalho inter-firmas, que, por definição, é difícil de ser transferida para qualquer lugar. Bancos locais desenvolvem especializações particulares, difíceis de serem aplicados a outros produtos. O mercado local de trabalho é caracterizado por um mix de qualificações compostas específicas de produtos. Daí a questão importante a pensar: em que isso difere da idéia de Haggett a respeito de concentração de escala em torno de um núcleo aleatório? É que as contribuições distintas, desta literatura, se fazem segundo desdobramentos. Primeiro se lida com a idéia do trancamento. Depois, as formas institucionais também são interpretadas por estes cientistas políticos do prisma da dependência encaminhada, ou em linha. O que por sua vez sugere aplicações na geografia política. 
Ron Martin (2010) fez recentemente alguns comentários críticos a respeito da noção de trancamento, ponderando que as habilidades das firmas de se ajustar à mudança e de abandonar o trancamento têm sido subestimadas. Elementos de sistemas de produção particulares podem ser frequentemente mudados sem destruir a dependência de linha e as vantagens competitivas que ela oferece. Há também o registro de distritos industriais particulares que experimentaram contínua inovação e renovação, e que continuaram proeminentes em setores particulares da economia. Contudo, e apesar destes argumentos, não é difícil de encontrar casos, na geografia humana, que parecem se ajustar à idéia do trancamento.

- Geografias nacionais urbanas, particularmente em países altamente concentrados, como no Reino Unido e na França, são exemplos. Qualquer tendência radical de mudança é esvaziada de antemão, pelo padrão já existente de investimentos infra-estruturais muito caros nas principais rodovias, ferrovias e aeroportos.

- $\quad$ O mesmo se aplica para o padrão de desenvolvimento suburbano de baixa densidade nos Estados Unidos. A aposta das companhias de petróleo, das seguradoras de automóveis e de propriedades, das companhias de amortização, sem mencionar as das remotas pequenas cidades e vilas que esperam entradas financeiras com a bonança, fazem virar fumaça qualquer alternativa que poderia, por exemplo, tornar factível transporte de massa mais barato,.

\section{Justaposições de chance de Massey.}

Finalmente chegamos ao trabalho de Doreen Massey sobre o papel de justaposições de chance, ou ao que ela se refere depois como a instância do acontecer na construção e transformação da geografia humana. Ela tem trabalhado sobre isto há algum tempo, desde o começo dos anos 1980. Embora a noção de justaposição de chance tenha permanecido como tema em andamento no seu pensamento, ele passou por algumas mutações.

O primeiro escrito que temos desta nova direção no seu pensamento é a metáfora geológica que ela introduziu no seu artigo de 1983. Anteriormente, ela já tinha pincelado a idéia de diferentes formas da divisão espacial do trabalho. Uma forma seria dependente de uma especialização regional baseada no produto, e uma outra forma, que se seguia, seria dependente da organização espacial da firma individualizada, em questão. Em 1983, no entanto, ela introduz a idéia de camadas superpostas de acumulação, cada uma 
correspondendo a uma forma diferente da divisão espacial do trabalho. $O$ caso que a interessava particularmente era o modo pelo qual a montagem leve, a do estabelecimento de montagem de emprego feminino, interagia com a mais velha, a de emprego dominantemente masculino, de uma divisão geográfica do trabalho anterior. Em particular, as implicações para as relações de sexo e classe.

Isto é seguido (1992) por uma distinção entre o que ela chama de localizações planejadas e não planejadas. Todas as localizações compreendem estes dois elementos. Uma firma planejará a sua localização em termos de acesso à mão-de-obra, de mercado, porém, haverá inevitavelmente um elemento não planejado. São aspectos da localização que não foram antecipados, e que podem ser tanto positivos como negativos. Considere-se que outras firmas também se localizaram no mesmo lugar, e elas podem acabar aparecendo como complementares e facilitando a capacidade competitiva da primeira. Ou elas podem criar efeitos negativos: alterando através dos salários que pagam os preços da moradia e deste modo impactando a demanda de salários dos trabalhadores.

Mais recente ainda, o seu trabalho sobre o papel da justaposição tempo - espaço sugere uma forte influência do tipo pós estruturalista (1999; 2005). Espaço, ela proclama, emerge das relações entre múltiplas narrativas de instâncias do acontecer. As influências e as condições chegam juntas para fazer dos lugares o que eles são. Uma vez que essas influências mudam, assim muda o caráter de um lugar. O futuro, no entanto, se encontra aberto. Os lugares devem ser entendidos como o encontro e o desencontro de elementos que previamente não são relacionados. São eventos espaço-tempo. A mais radical de todas as implicações no entendimento de Massey é de que não pode haver tendências universais ${ }^{3}$

A partir do seu livro com Allen e Cochrane (1998) sobre o Sudeste da Inglaterra temse uma idéia sobre o que é talhado por estas idéias. Trata-se de idéias que fazem parte de uma tentativa para 'repensar a região', esta expressão estando posta como sub-título do livro. No livro, o Sudeste, expressão emergida durante os anos 1980, é tomado como tendo sido construído por um encontro particular de eventos, condições e narrativas. A área é definida pelo seu status como sendo uma região `bem sucedida`que se salienta do resto do país, em termos de seu crescimento. Este crescimento pode, então, ser entendido como o resultado de chance, em tempo e espaço, de diversas diferentes dinâmicas. Uma indústria chave do crescimento tem sido a de serviços financeiros. O que tem sido importante para a economia 
de Londres, durante pelo menos um século. Recebeu, no entanto nova erupção de energia como resultado das reformas de governo dos anos 1980. Bastante independente disto, e provendo mais um ímpeto ao crescimento regional, tem sido a expansão das telecomunicações, dos serviços computacionais e da pesquisa e desenvolvimento independente em vários centros. Isto se deve, de algum modo, à habilidade da capacidade de atrair trabalho qualificado certo, em virtude da atração que a área tem para se viver nela. Contudo, não é de nenhum modo a razão única. A presença, por chance, no Sudeste, das duas maiores Universidades de pesquisa, a Oxford e a Cambridge, teve a sua importância, particularmente no caso da segunda, que se tornou o núcleo do país equivalente do Vale do Silício. Houve também localizações anteriores, como a da indústria farmacêutica em Hertfordshire, bem ao norte de Londres, e da indústria aeronáutica em Bristol, no extremo oeste da região.

Massey não tem estado sozinha neste tipo de debate. Chris Philo (1994) tem falado da geografia por trás da história e proposto uma 'história geográfica'. Através desta expressão ele sugere que as geografias passadas explicam as maiores mudanças havidas na história, como a emergência do Estado moderno ou a formação de identidade racial. É possível construir interpretação similar de globalização: a mistura do fim de Bretton Woods com a tendência para trocas cambiais flutuantes; o choque do preço de petróleo dos anos 70; as revoluções do container e da tecnologia de informática; a ascensão dos novos países emergentes industrializados; Thatcher e Reagan como lideres carismáticos; petróleo britânico e o foco em serviços financeiros, já que a indústria foi exprimida pelo curso subsequiente dos recursos; a União Européia que foi se estabelecendo desde muito antes da globalização; o desenvolvimento desigual e o problema tido pelos Estados Unidos e pelo Reino Unido, confrontando em particular a competição das firmas alemãs e japonesas; e a procura do FMI por um novo papel, devido à quebra dos acordos de Bretton Woods.

\section{Discussão}

Considerando estas diversas contribuições, a primeira coisa a apontar são as claras superposições e as complementaridades entre as mesmas. A produção de realimentações positivas, enfatizada na teoria do desenvolvimento dependente encaminhado, encontra claramente um precedente nos primeiros trabalhos de Hagerstrand e no que Haggett chamou de 'concentrações de escala em torno de um núcleo aleatório'. Encontram-se também algumas 
complementaridades. Em relação ao desenvolvimento encaminhado, Ron Martin (2010) observou que, o que é chamado de 'o modelo canônico', não oferece diretiva para o porquê e para o como uma nova linha de desenvolvimento emerge, onde e quando. Assume-se implicitamente, através do que ele chama de 'paisagem virgem', algo indiferenciado em termos das condições que pudessem nos ajudar a entender a emergência de um desenvolvimento dependente de linha em lugares particulares. Massey, no entanto, nos ajuda a entender como a diferenciação pode ocorrer. Por outro lado, a abordagem de Massey também possui algumas sérias reduções e quero aproveitar este fato para seguir numa discussão mais geral sobre como devemos entender chance no fazer de geografias humanas.

O problema mais notável é o de não haver mecanismo que possa selecionar, para se considerar ou não, as várias influências que chegam juntas a um determinado lugar. A questão sobre o que foi selecionado é saber quais deles são eventos aleatórios, que aspectos dos diversos 'chegados juntos`ou dos 'arranjos de acontecimentos de instâncias`são pertinentes; e o que é descartado por ser insignificante ou que falhou ao ser experimentado. Porém Massey não nos oferece nenhuma indicação de como isso possa ser trabalhado. Parece-me que, aqui, considerar o processo da acumulação é central. Algumas coisas podem ser tomadas como vantagens, seja pelo capital, seja pelo trabalho, a favor de um, mas, não do outro, conforme tentem determinar as condições do processo de acumulação, ou resistir ao mesmo.

Isto também lança uma luz mais cética quanto ao acontecer de instâncias e quanto a tese das justaposições aleatórias serem sempre encontradas. Incerteza não é algo ao qual o capital seja passivo. Ao contrário, ele tenta antecipar eventos e controla-los, bem como, limitar surpresas. Ele toma medidas para limitar a incerteza, através de superação sobre rivais, através de integrações verticais de suas operações, e através da dispersão dos riscos por diversos mercados diferentes. As firmas capitalistas planejam, e uma das coisas que elas planejam é relativo â incerteza, e o mesmo fazem os Estados capitalistas. Políticas de seguro são tomadas como que para retirar o 'natural' dos 'desastres naturais'. Por sua vez, as companhias de seguro tratam de minimizar as possibilidades de perdas pelo imprevisto ${ }^{4}$. Em adição, muito do que chega junto num lugar, já é intencionalmente trazido junto, montado. $\mathrm{O}$ capital intervém puxando para juntar distantes, sejam idéias a respeito de organizar a produção, do Japão, ou trabalhadores do México. Os migrantes pioneiros de Hagerstrand não necessitam obrigatoriamente, de atuar sozinhos para encorajar outros a segui-los. Eles podem ter o apoio ativo dos empregadores, prometendo trabalho a novos chegados. De fato, este Geo UERJ - Ano 14, nº. 23, v. 2, $2^{\circ}$ semestre de 2012 p. 312-330 
suporte, um recrutamento deliberado, pode até ser a razão de eles serem os primeiros a estarem lá.

Preocupações semelhantes podem ser levantadas a respeito do trabalho de Hagerstrand. Seu trabalho sobre difusão foi criticado exaustivamente por Gregory (1985) há mais de 25 anos. Uma das questões maiores que ele levantou foi a inexistência nos estudos de Hagerstrand de qualquer referência às condições sociais para a inovação. $O$ papel das diferenciações sociais para a adoção, e o da luta de classe como condição da inovação, não foram levados em conta. Também, estranhou a ausência a respeito das conseqüências sociais da inovação, por exemplo, como ela poderia afetar capacidades competitivas e, portanto, novas diferenciações sociais. O trabalho de Hagerstrand sobre migração recebeu atenção crítica menor. Um obvio lembrete seria de que seu argumento necessita ser enquadrado em referências relativas aos mercados capitalistas de trabalho, porém, se pode ir além. Quero apresentar aqui dois pontos. O primeiro é quanto ao número de desvios, que certamente ocorrem nas cadeias de migrações, em relação ao que se sabe atualmente sobre a geografia dos mercados de trabalho. Segundo Ian Gordon, estes são acentuadamente segmentados. Para a maioria das pessoas os mercados de trabalho são totalmente locais. As pessoas encontram trabalho através de conversa, ou alguma notícia do jornal local sobre mais emprego de natureza não técnica ou profissional. Movimentos entre diferentes mercados de trabalho urbano ocorrem, porém, amplamente confinados aos jovens, sem compromissos de família, ou possuidores de residência própria. Por outro lado, a migração de longa distância é prerrogativa da classe gerencial técnico-profissional. Neste caso o recrutamento se realiza através de jornais nacionais de negócios e por um processo de entrevista financiada pela organização empregadora. O risco para o aplicador é assim minimizado. Neste sentido, a cadeia da migração também funciona para minimizar riscos, quando ela é provida de uma comunidade receptiva, através de empregos e moradia assegurados, no lugar destinado.

Segundo, a cadeia de migração descrita por Hagerstrand parece ser aquela que, de modo particular, facilita a transição de formas de produção précapitalistas passando por dissolução, para formas capitalistas. O que seria uma das razões dela ter atraído tanta atenção da parte dos antropólogos. Chegam, à mente, as imagens dos movimentos de gente do México rural para áreas do Sudoeste estadunidense, assim como, anteriormente, as de afro-americanos de um Sul, que estava substituindo a meação por trabalho assalariado, para cidades do Nordeste. Nestes casos, as intensas distâncias sociais, incluídas as dos valores alienantes das

Geo UERJ - Ano 14, no. 23, v. 2, $2^{\circ}$ semestre de 2012 p. 312-330

ISSN: 1415-7543 E-ISSN: 1981-9021

http://www.e-publicacoes.uerj.br/index.php/geouerj 
comunidades hospedeiras, sugerem a importância contida na comunidade migrante. Deste modo, de novo, o quanto de 'chance' se encontra nestas migrações, se torna questionável.

\section{Uma conclusão.}

Como, então, podemos ter em vista o papel de chance na produção de geografias, particularmente as capitalistas? Sugiro quatro possibilidades. A primeira é a de que o mundo é todo ele chance. È a postura de Massey, se tomada literalmente, e não vejo razão para se duvidar de ser esta a sua posição, uma vez que, como apontei acima, ela recuou das assunções anti-essencialistas. O que se encontra implícito quando ela enfatiza o que chama de a instância do acontecer. Por razões já apresentadas penso que isto é inaceitável.

A segunda reconhece a existência de ambos, processos de chance e processos estruturados, ou, dito de outro modo, a presença de contingência e de necessidade. Minha preocupação principal é que isto implicaria numa aguda divisão entre chance e estrutura, entre contingência e necessidade, o que quero desafiar abaixo.

O terceiro modo de ver a questão é que as estruturas sociais, que regulam processos sociais, se constituem a partir de eventos de chance. O que lembra a geografia da história de Philo (1994). Penso que é possível concordar com a idéia da estrutura social se formando deste modo. Já fiz tal manifestação ao tratar da globalização. Mais fundamental do que a globalização é o capitalismo que, afinal, o dirige. No entanto, igualmente, se pode considerar o capitalismo como um acidente, fundado em vários eventos que se encontraram no período dos Tudor. Eventos que apressaram a criação de mercados de trabalho e de terras. Penso em eventos como a dissolução de mosteiros e a venda das terras para favoritos da corte, enquanto, ao mesmo tempo, monges e freiras ficavam sem meios de subsistência. Outro evento seria o aumento do comércio da lã. "O fazer de ovelhas devora o homem”, se queixava Thomas More na Utopia, num trecho devotado para a compreensão do porque no período Tudor, aqueles que acreditavam ter direitos hereditários de acesso à terra, direitos que não podiam vender, se viram despojados deles, por uma força maior que fazia com que eles fossem sendo substituídos por ovelhas em engorda dos senhores feudais.

Contudo, não creio se possa reduzir o capitalismo tão facilmente. Existe um elemento de chance quanto à determinação de quando e onde o capitalismo primeiro iria emergir, porém irei concluir este trabalho argumentando que estes eventos devem se vistos como 
providos de um quadro existente atrás, habilitando condições que não devem nada à chance. Existem tendências persistentes na história humana, apesar do que dizem os pós-modernistas. Eu argumentaria, por exemplo, com incontestável do que se segue: i) que a habilidade das pessoas de produzir cresceu ao longo to tempo, praticamente de forma monotônica; o crescimento se tornou muito rápido com o capitalismo, mas, a Inglaterra feudal se encontrava anos-luz à frente da Idade da Pedra ou do Neolítico; ii) que isto tem se dado devido a uma crescente socialização de produção, notavelmente, pelo desenvolvimento da divisão do trabalho; iii) que o desenvolvimento da divisão do trabalho, por sua vez, talhou o desenvolvimento das trocas e dos meios para as trocas, onde o dinheiro aparece como proeminente; iv) o crescimento da habilidade de produzir tem aberto a propensão de produzir excedente e consequentemente uma sociedade de classe, na qual uns produzem o excedente e outros, uma classe exploradora, toma posse dele, para seus propósitos próprios. Em outras palavras, ao final da Idade Média, um número de condições para a transição ao capitalismo já estavam estabelecidas, inclusive, mercados. Se não se tratava ainda de mercados de trabalho ou de terras, no entanto, havia um marcante grau de diferenciação social, inclusive quanto ao acesso aos meios de força física, como resultado das relações de classe entre senhores e servos, e o dinheiro. Em outras palavras, se o capitalismo foi um acidente, foi um acidente aguardando aparecer.

Concentrando-nos sobre a emergência do capitalismo. Uma vez que o capitalismo se instala e passa a rolar, então a chance continua a exercer um papel. O modo pelo qual isto se realiza pede um exame cuidadoso. Capitalismo é um sistema expansivo de produção. As firmas precisam crescer. A intensidade da competição as deixa sem alternativa, caso não queiram abandonar os seus negócios. O desenvolvimento capitalista tem sido, segundo um dado ponto de vista, uma sucessão de inovações que vai reunindo todos os momentos da produção. Não apenas os técnicos, mas, também, os institucionais, os geográficos, as relações empregador/empregado, os discursivos e outros. Há algo de imprevisível a respeito desses momentos. Eles só podem ser explicados após a sua ocorrência, e Massey pode ser vista como apontando para tal fato: para o papel da justaposição aleatória de formas institucionais, inovações técnicas, e idéias. Uma justaposição que como se trancasse estas formas dentro de um dado lugar, num modo associado ao desenvolvimento dependente de um encaminhamento. E estas formas podem revolucionar a paisagem, como nos casos dos subúrbios de baixa densidade, dos novos distritos industriais associados a novos setores 
emergentes, ou, em nível mais micro, como no padrão de gentrificação de uma dada cidade. É nestes termos que podemos pensar a idéia de geografias possíveis. Ainda assim, elas permanecem como geografias capitalistas, já que sem as condições, o quadro de incentivos baixado pelo capital, não poderiam, possivelmente, existir.

Nota do tradutor. Além da elevada qualidade acadêmica oferecida para o debate do tema, este trabalho traz uma observação particular para o geógrafo brasileiro. Ao contrário do que ocorreu aqui, onde fundamentalismos ideológicos, mobilizados para esconder interesses, conduziram ao total 'esquecimento` da revolução quantitativa espacial dos anos 60/70, o trabalho recupera produções realizadas naquela linha para enriquecer o pensamento crítico de hoje na área social. P.G.

Referências:

ALLWN J, MASSEY D e COCHRANE A. Rethinking the Region: Spaces of NeoLiberalism. London Routledge. 1998.

BOISSEVAIN, J. The Italian Montreal: Social Adjustment in a Plural Society, Ottawa, Studies of the Royal Commission on Bilingualism and Biculturalism, vol.7. 1970.

CURRY, L. Chance and Landscape em J W HOUSE editor, Northern Geographical Essays, Department of Geography, University of Newcastle-Upon-Tyne. 1966.

GORDON, I. Migration in a Segmented Labor Market, Transaction of the Institute of British Geographers, NS 20:2, 139-155. 1995.

GREGORY, D. Suspended Animation: The Stasis of Diffusion Theory, Capítulo 13 de Gregory, D e Urry, J, 1985, Social Relations and Spatial Structure, London, Macmillan. 1985. 
HAGERSTRAND, T. Migration and area: Survey and Sample of Swedish Migrations Fields and Hypothetical Considerations on their Genesis, Lund Studies in Geography, B, Human Geography, 13, 27-158. 1957.

HAGGETT, P. Locational Analysis in Human Geography, London, Edward Arnold. 1965.

MARTIN, R, L. Rethinking Regional Path Dependence: Beyond Lock-in to Evolution, Economic Geography 86:1, 1-27. 2010

MASSEY, D. Industrial Restructuring as Class Restructuring: Production Decentralization and Local Uniqueness, Regional Studies, 17:2, 73-89. 1983.

. Politics and Space/Time, New Left Review, 165, 65-84. 1992.

. Spaces of Politics, Capítulo 14 em D Massey, J Allen e Sarre editores, Human

Geography Today, Cambridge, Polity Press. 1999.

. For Space, London, Sage. 2005.

PHILO, C. History, Geography and the 'Still Greater Mystery` of Historical Geography, Capítulo 10 de D Gregory, R Martin e G Smith editores, Human Geography: Society, Space and Social Science, Minneapolis, Minnesota University Press. 1994.

STORPER, M, e WALKER, R. The Capitalist Imperative, Oxford, Blackwell. 1989.

TEAFORD, J. C. The Unheralded Triumph: City Government in America, 1870-1900, Baltimore, Johns Hopkins University Press. 1984.

\footnotetext{
${ }^{1}$ Um contraste interessante é o da gentrificação rural na Inglaterra. Há 50 anos atrás, a maioria dos vilarejos eram quase totalmente locais da classe trabalhadora, com poucos elementos de remanência das gentes da terra. Agora, virtualmente, todos eles possuem moradias restauradas e residentes afluentes, até extremamente afluentes. A propriedade rural, independente de sua localização, é procurada por toda parte. É difícil, atualmente, achar um vilarejo que não tenha sido gentrificado.

${ }^{2}$ Por outro lado, muitas vezes, a rápida superação pode ser operada por uma firma, ou grupo de firmas, que mostram o caminho para as outras. A China, por exemplo, o tem demonstrado, de que pode produzir para o mercado mundial, que seu governo pode prover preços estáveis e que, apesar de suas credenciais comunistas, observa is direitos de propriedade e deste modo participando do que já pode ser visto como uma 'corrida pelo ouro'.Os altos níveis de lucro que são obtidos lá, atraem então os supridores.

${ }^{3}$ Embora e forma bastante interessante, o fato é que ela se retraiu da posição anti-essencialista. "As imaginações geográficas (por exemplo, as do desenvolvimento regional e as do desenvolvimento regional desigual) não são simples espelhos; elas são, em certo sentido, figurações constitutivas. Em certo sentido, elas 'produzem’ o
} 
mundo no qual vivemos e no interior do qual elas mesmas são construídas. Por outro lado, já o fato de haverem intentos de intervenção, implica numa rejeição desta posição, o que nos prenderia numa armadilha de linguagem da qual não haveria saída. (Em outras palavras me vejo obrigada, de forma relutante, a seguir os passos de Downing Street, oferecendo uma outra metáfora/estória/imaginação, cujas relações com a 'realidade extradiscursiva' da divisão Norte-Sul é de que ela é não existente, ou é desconhecida)". (Progress in Human Geography, 2001:10).

${ }^{4}$ Durante o século 19, as empresas de seguro foram ativas para elevar o padrão de proteção contra incêndios, como no aumento da pressão da água nos hidrantes e na compra de equipamentos para driblar fogos em imóveis de múltiplos andares. Veja Teaford (1984)

Artigo encaminhado para publicação em setembro de 2012.

Artigo aceito para publicação em setembro de 2012. 